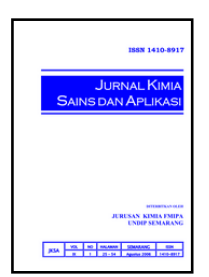

\title{
Pengaruh Konsentrasi Surfaktan CTAB (Cetyltrimethylammonium bromide) pada Modifikasi Lempung dengan Oksida Besi sebagai Pemilar
}

\author{
Irine Ayu Febiyanti ${ }^{a}$, Ahmad Suseno $^{a^{*},}$ Priyono $^{\text {a }}$ \\ a Physical Chemistry Laboratory, Chemistry Department, Faculty of Sciences and Mathematics, Diponegoro University, Jalan Prof. \\ Soedarto, Tembalang, Semarang \\ * Corresponding author: suseno@live.undip.ac.id
}

\section{Article Info}

Keywords:

clay, pillarization, iron oxide,

cetyltrimethylammonium bromide surfactant
Kata Kunci:

lempung, pilarisasi, oksida besi, surfaktan cetyltrimethylammonium bromide

\begin{abstract}
This study is about the modification of clay by pillaring with iron oxide and using surfactant CTAB as swelling agent. The purpose of this study was to determine the effect of the CTAB concentration on the clay modification with iron oxide as pillaring agent. The research was conducted with the initial stages by clay purification to separate the impurities in natural clay then clay was activated with $\mathrm{NaCl}$ solution to obtain the Na homoionic clay. Modification process was conducted by adding the CTAB with various concentrations and the results were characterized using FTIR and XRD. Clay pillarization was carried out by adding iron polyoxocation solution then calcining. The results were characterized using BET. FTIR spectra showed that the CTAB modified clay has been successfully synthesized. The XRD diffractogram showed that the intercalation of CTAB surfactant caused increasing of basal spacing on the CTA-Mont from the initial basal spacing $1.59 \mathrm{~nm}$ to 2.35 $\mathrm{nm}$. BET analysis result showed the increasing of average pore radius, surface area and total pore volume of Iron oxide-Mont1 from $5.76 \mathrm{~nm}, 52.83 \mathrm{~m}^{2} / \mathrm{g}$ and $0.15 \mathrm{~cm}^{3} / \mathrm{g}$ to $8.14 \mathrm{~nm}, 80.73 \mathrm{~m}^{2} / \mathrm{g}$, and $0.33 \mathrm{~cm}^{3} / \mathrm{g}$.
\end{abstract}

\section{Abstrak}

Telah dilakukan penelitian tentang modifikasi lempung dengan cara pilarisasi menggunakan oksida besi dengan bantuan surfaktan CTAB. Penelitian ini bertujuan untuk menentukan pengaruh konsentrasi surfaktan CTAB pada proses modifikasi lempung dengan oksida besi sebagai pemilar. Penelitian ini dilakukan dengan tahap awal yaitu preparasi lempung untuk memisahkan pengotor dalam lempung alam kemudian diaktivasi menggunakan larutan $\mathrm{NaCl}$ dan diperoleh lempung homoionik Na. Modifikasi lempung dilakukan dengan penambahan surfaktan CTAB dengan variasi konsentrasi dan hasilnya dikarakterisasi menggunakan FTIR dan XRD. Pilarisasi lempung dilakukan dengan larutan pemilar polioksokation besi kemudian dikalsinasi dan hasilnya dikarakterisasi menggunakan BET. Spektra FTIR menunjukkan bahwa modifikasi lempung menggunakan surfaktan CTAB telah berhasil dilakukan. Difraktogram XRD menunjukkan bahwa interkalasi surfaktan CTAB menyebabkan peningkatan basal spacing terbaik pada CTA-Mont1 sebesar 2,35 $\mathrm{nm}$ dari basal spacing lempung awal sebesar 1,59 nm. Hasil analisis BET menunjukkan peningkatan jari-jari pori rata-rata, luas permukaan, dan volume pori total Oksida Besi-Mont1 dari $5,76 \mathrm{~nm}, 52,83 \mathrm{~m}^{2} / \mathrm{g}$ dan $0,15 \mathrm{~cm}^{3} / \mathrm{g}$ menjadi 8,14 $\mathrm{nm}, 80,73 \mathrm{~m}^{2} / \mathrm{g}$, dan $0,33 \mathrm{~cm}^{3} / \mathrm{g}$. 


\section{Pendahuluan}

Lempung (clay) merupakan material alam yang memiliki struktur berlapis dan berpori. Lempung digunakan sebagai penukar ion, adsorben, dan katalis untuk berbagai jenis reaksi organik [1]. Terkait aplikasinya sebagai adsorben dan katalis, penggunaan lempung memiliki keterbatasan karena luas permukaan dan stabilitas termalnya rendah. Oleh karena itu diperlukan modifikasi struktur lempung untuk meningkatkan luas permukaan dan stabilitas termalnya dengan pilarisasi lempung [2].

Pilarisasi lempung merupakan pengembanan oksida logam ke dalam antarlapis lempung [1]. Lempung terpilar memiliki luas permukaan, volume pori serta stabilitas termal yang lebih tinggi daripada lempung alam [2]. Menurut Dvininov dkk. [3], proses pembuatan lempung terpilar dapat dilakukan dengan cara memasukkan surfaktan kationik terlebih dahulu sebelum memasukkan polioksokation logam pemilar. Salah satu jenis lempung terpilar berdasarkan jenis pilar oksida logamnya adalah lempung terpilar oksida besi. Lempung terpilar oksida besi dapat digunakan sebagai katalis maupun adsorben dalam proses-proses yang melibatkan zat warna misalnya fotodegradasi, penjernihan air, adsorben gas $\mathrm{CO}_{2}$ dan $\mathrm{H}_{2}$ [4].

Hasil penelitian Dvininov dkk. [3] menunjukkan bahwa interkalasi surfaktan sebelum polioksokation logam pemilar menyebabkan pembesaran jarak antarlapis lempung terpilar lebih optimal. Menurut Wang $d k k$. [5], surfaktan yang paling optimal dalam sintesis lempung terpilar adalah CTAB. Surfaktan memiliki struktur yang besar dan dapat memperbesar basal spacing $\left(\mathrm{d}_{\mathrm{oo1}}\right)$ lempung secara sementara sehingga polioksokation logam pemilar dapat terinterkalasi secara optimal di dalam antarlapis lempung. Penyusunan surfaktan di dalam antarlapis lempung berbeda-beda sesuai dengan konsentrasi surfaktan yang digunakan [6]. Berdasarkan kajian di atas, maka dilakukan penelitian mengenai pengaruh konsentrasi surfaktan pada proses modifikasi lempung dengan oksida besi sebagai pemilar.

\section{Metode Penelitian}

\section{Alat dan Bahan}

Seperangkat alat gelas standar, timbangan digital Kern ALS 220-4N, magnetic stirrer/hotplate Thermo Scientific Cimarex, sentrifuge refrigerate Universal 320R, oven ARISTON type F-16-EM-in-02, penumbuk, ayakan 170 mesh, furnace Vulcan 3-130, EDS JEOL JSM6510LA, FTIR Shimadzu Prestige 21, XRD Shimadzu Lab $\mathrm{X}$ Seri 6000, BET Quantachrome Instruments version 11.o. Lempung alam dari Thailand, $\mathrm{NaCl}$ (p.a. Merck), $\mathrm{FeCl}_{3} .6 \mathrm{H}_{2} \mathrm{O}$ (p.a Merck), $\mathrm{NaOH}$ (p.a, Merck), surfaktan CTAB (p.a.Merck), AgNO3 (p.a. Merck), dan akuades.

\section{Preparasi Lempung Alam}

Dua ratus gram padatan lempung alam dari Thailand dicampur dengan $1600 \mathrm{ml}$ akuades, diaduk kemudian distirer selama 15 menit pada suhu kamar.
Campuran didiamkan beberapa menit hingga terbentuk endapan kuarsa di dasar wadah. Endapan kuarsa dihilangkan dengan cara dekantasi. Campuran lempung bebas kuarsa dipisahkan dengan sentrifugasi 5000 rpm selama 15 menit pada suhu ruang. Endapan lempung dipisahkan dan dikeringkan pada suhu $800 \mathrm{C}$ selama 24 jam. Setelah kering, lempung alam bebas kuarsa digerus dan diayak 170 mesh.

\section{Aktivasi Lempung Alam}

Enam puluh gram padatan lempung alam bebas kuarsa dicampur dengan $600 \mathrm{ml} \mathrm{NaCl} 1 \mathrm{M}$. Campuran tersebut distirer pada $600 \mathrm{C}$ selama 3 jam dan didiamkan selama 24 jam. Endapan lempung dipisahkan dengan sentrifugasi $5000 \mathrm{rpm}$ selama 15 menit. Endapan lempung yang diperoleh dicuci dengan akuades hingga bebas ion $\mathrm{Cl}-$. Keberadaan ion $\mathrm{Cl}$ - diuji menggunakan $\mathrm{AgNO}_{3}$. Setelah bebas ion $\mathrm{Cl}-$, endapan lempung dikeringkan pada suhu $800 \mathrm{C}$ selama 24 jam. Padatan lempung homoionik yang diperoleh selanjutnya dianalisis KTK (Kapasitas Tukar Kation) [3].

\section{Modifikasi Lempung dengan Surfaktan CTAB}

Lima gram padatan lempung homoionik dicampur dengan surfaktan CTAB dengan variasi konsentrasi masing-masing 0,024 M ; 0,048 M; 0,072 M. Campuran distirer pada suhu $600 \mathrm{C}$ selama 8 jam kemudian didiamkan selama 24 jam. Endapan lempung dipisahkan dengan sentrifugasi 5000 rpm selama 15 menit hingga bebas ion bromida ( $\mathrm{Br}-$ ). Endapan lempung dikeringkan pada suhu $800 \mathrm{C}$ selama 24 jam dan diperoleh lempung modifikasi surfaktan (LMS).

\section{Pembuatan Lempung Terpilar Oksida Besi}

Larutan pemilar dibuat dengan melarutkan 8,11 gram $\mathrm{FeCl}_{3} \cdot 6 \mathrm{H}_{2} \mathrm{O}$ ke dalam $150 \mathrm{ml}$ akuades kemudian ditambah dengan $300 \mathrm{~mL}$ larutan $\mathrm{NaOH} \mathrm{0,2} \mathrm{M} \mathrm{tetes} \mathrm{demi}$ tetes sambil distirer selama 3 jam pada suhu ruang. Larutan pemilar dicampurkan ke dalam LMS ( $2 \%)$ tetes demi tetes sampai habis sambil distirer kemudian dilanjutkan stirer selama 2,5 jam pada suhu ruang lalu didiamkan selama 24 jam. Endapan dipisahkan dengan sentrifugasi 5000 rpm selama 15 menit. Endapan yang diperoleh dicuci dengan akuades sampai bebas ion $\mathrm{Cl}-$. Setelah itu endapan dikeringkan pada suhu $600 \mathrm{C}$ selama 24 jam kemudian dikalsinasi pada suhu $5500 \mathrm{C}$ selama 4 jam. Lempung terpilar besi oksida yang diperoleh selanjutnya dianalisis menggunakan BET [7].

\section{Hasil dan Pembahasan}

\section{Karakterisasi EDS Lempung Alam}

Lempung alam dikarakterisasi menggunakan EDS untuk mengetahui komposisinya. Hasil yang diperoleh memberikan informasi komposisi unsur dalam lempung alam adalah $0,19 \% \mathrm{Mg} ; 0,66 \% \mathrm{~K} ; 1,99 \% \mathrm{Fe} ; 2,12 \% \mathrm{Ca}$; 4,53\% Al; 36\% C; dan 52,75\% Si dan komposisi oksida logam adalah 1,40\% K2O; 1,55\% MgO; 2,66\% CaO; $3,20 \% \mathrm{FeO} ; 9,76 \% \mathrm{C} ; 10,36 \% \mathrm{Al} 2 \mathrm{O} 3$; dan $71,06 \% \mathrm{SiO} 2$. Berdasarkan data tersebut dapat diketahui bahwa komposisi utama lempung alam adalah senyawa silika dan alumina. 


\section{Karakterisasi XRD Lempung Alam}

Hasil karakterisasi XRD lempung alam dapat dilihat pada gambar 1.

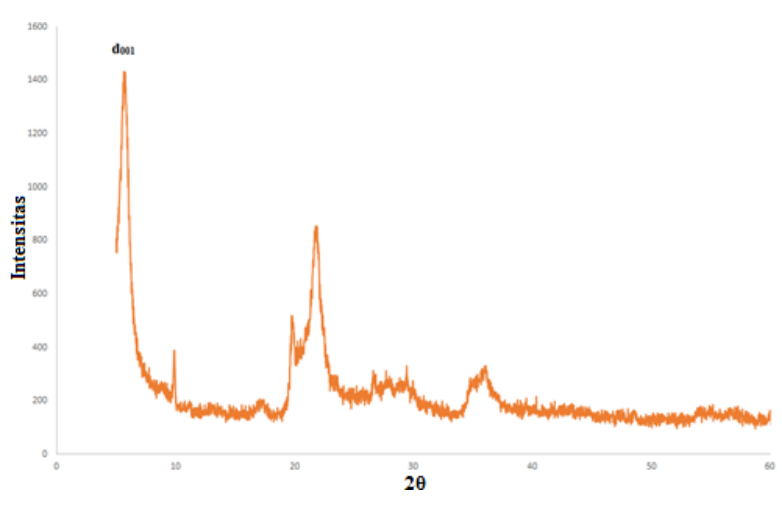

Gambar 1. Difraktogram lempung alam

Hasil analisis XRD lempung alam diolah dengan software Match! untuk mencocokkan data hasil analisis XRD lempung alam dengan data standar sehingga diperoleh hasil pada gambar 2.

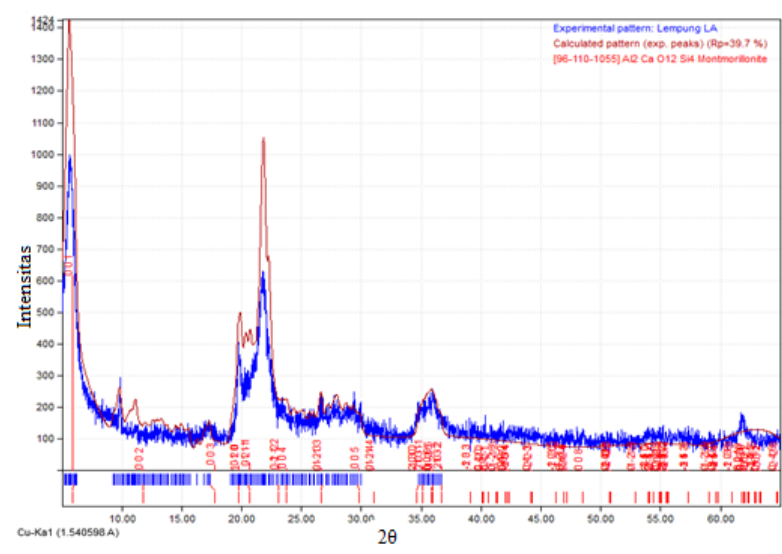

Gambar 2. Hasil pengolahan data XRD lempung alam dengan software Match

Hasil pencocokan menunjukkan bahwa jenis lempung alam yang digunakan adalah Camontmorilonit. Hasil pencocokan tersebut diperkuat dengan pengolahan data XRD lempung alam dengan software GSAS dimana fasa yang diusulkan adalah Camontmorilonit. Hasil pengolahan data XRD lempung alam menggunakan software GSAS dapat dijelaskan pada tabel 1. Data pada tabel 1 menunjukkan acceptable fit yang cukup baik. Kesesuaian antara fasa yang diusulkan dengan fasa sampel tertera dalam gambar 3.

Tabel 1: Hasil pengolahan data XRD lempung alam menggunakan software GSAS

\begin{tabular}{cc}
\hline \multicolumn{2}{c}{ Material lempung alam } \\
\hline $\mathrm{wRp}(\%)$ & $11,85 \%$ \\
\hline $\mathrm{Rp}(\%)$ & $8,80 \%$ \\
\hline Chi-squared $\left(\chi^{2}\right)$ & 3,08 \\
\hline $\begin{array}{c}\text { Ca- } \\
\text { montmorilonit }\end{array}$ & $\mathrm{Al}_{2} \mathrm{CaO}_{12} \mathrm{Si}_{4}$ \\
\hline Parameter kisi & $\begin{array}{c}\mathrm{a}=0,52 \mathrm{~nm} ; \mathrm{b}=0,90 \mathrm{~nm} ; \mathrm{c}=1,50 \\
\mathrm{~nm}, \alpha=90,00^{\circ} \beta=90,00^{\circ} \gamma=90,00^{\circ}\end{array}$ \\
\hline Densitas & $1,80 \mathrm{~g} / \mathrm{cm}$ \\
\hline
\end{tabular}

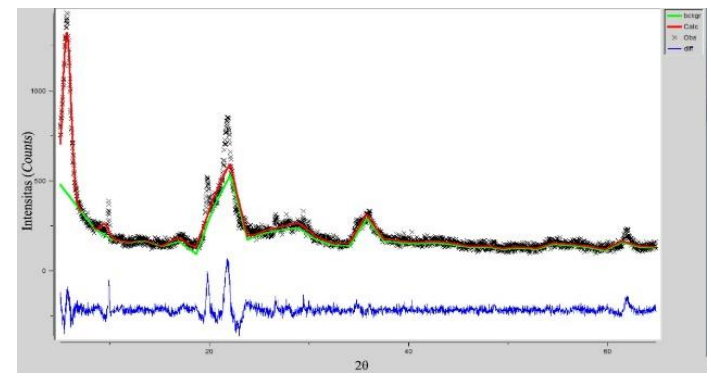

Gambar 3. Grafik kesesuaian fasa yang diusulkan dengan fasa sampel

Kurva hitam merupakan kurva data XRD lempung alam sedangkan kurva merah merupakan kurva teroritis hasil perhitungan GSAS yang didapat dari COD. Selisih antara kurva XRD lempung alam dengan kurva teoritis digambarkan pada kurva biru (kurva residu). Puncak yang terdapat pada kurva biru menunjukkan adanya fasa yang belum dimasukkan dalam proses pencocokan. Hasil pengolahan data XRD lempung alam menggunakan software Match! dan GSAS menunjukkan kesesuaian dengan penelitian yang dilakukan oleh beberapa peneliti dimana puncak $\mathrm{d}_{001} \mathrm{Ca}$-montmorilonit pada kisaran 1,50 nm. Penelitian Xue dkk. [8] dan Yuan dkk. [7] juga menyatakan bahwa basal spacing Camontmorilonit masing-masing sebesar $1,57 \mathrm{~nm}, 1,54$ $\mathrm{nm}$, dan 1,50 nm.

Hasil Karakterisasi FTIR Lempung Alam dan Lempung Modifikasi Surfaktan CTAB

Kedua spektra FTIR pada gambar 4 menunjukkan munculnya puncak tajam pada bilangan gelombang $794,67 \mathrm{~cm}^{-1}$ yang mengindikasikan keberadaan vibrasi ulur Si-O [9] dan $918,12 \mathrm{~cm}^{-1}$ yang mengindikasikan vibrasi ulur Si-O pada lapisan silika tetrahedral [10]. Puncak pada 462,92 $\mathrm{cm}^{-1}$ menunjukkan vibrasi tekuk SiO. Puncak pada bilangan gelombang $3626,17 \mathrm{~cm}^{-1}$ dan $3425,58 \mathrm{~cm}^{-1}$ menunjukkan adanya ikatan Al-O (O dari gugus $\mathrm{OH})$.

Spektra FTIR CTA-montmorilonit menunjukkan puncak tajam pada bilangan gelombang 2924,09 $\mathrm{cm}^{-1}$ dan $2854,65 \mathrm{~cm}^{-1}$ menunjukkan keberadaan vibrasi ulur asimetris dan simetris dari $\mathrm{C}-\mathrm{H}$ surfaktan CTAB [11]. Puncak pada bilangan gelombang $1473,62 \mathrm{~cm}^{-1}$ yang menyatakan vibrasi tekuk gugus $\mathrm{N}-\mathrm{C}$ surfaktan CTAB dimana puncak tersebut tidak terdapat pada spektra FTIR Ca-montmorilonit. Hal ini menunjukkan bahwa antarlapis lempung telah diinterkalasi oleh kation $\mathrm{CTA}^{+}$.

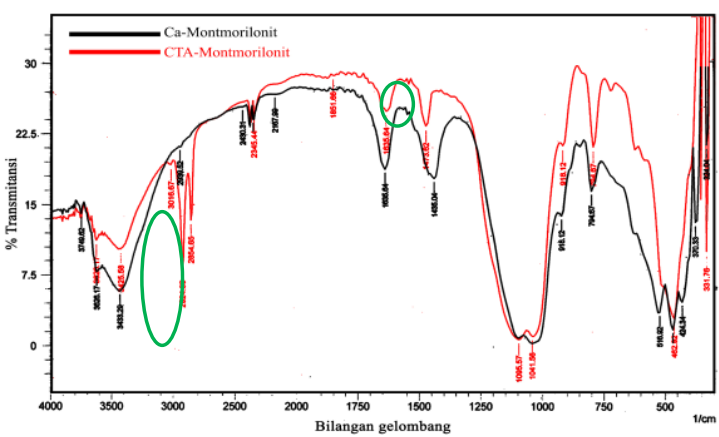

Gambar 4. Perbandingan spektra FTIR Camontmorilonit dan CTA-montmorilonit 
Hasil Karakterisasi XRD Lempung Alam dan Lempung Modifikasi Surfaktan CTAB

Perbandingan hasil analisis XRD Ca-montmorilonit dan CTA-montmorilonit dengan variasi konsentrasi CTAB dapat dilihat pada gambar 5 .

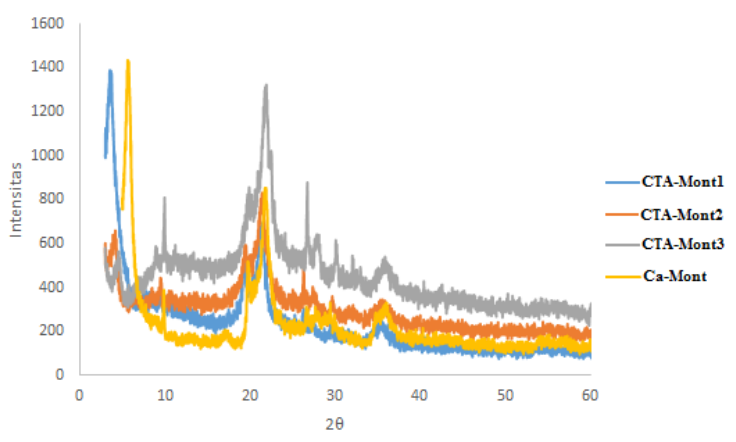

Gambar 5. Difraktogram Ca-montmorilonit dan CTAmontmorilonit

Gambar 5 menunjukkan pengaruh penambahan surfaktan terhadap basal spacing lempung. Sampel yang dianalisis adalah $\mathrm{Ca}-$ Mont (Ca-montmorilonit), CTAMont1 (CTA-montmorilonit dengan konsentrasi CTAB $0,024 \mathrm{M}$ ), CTA-Mont2 (CTA-montmorilonit dengan konsentrasi CTAB 0,048 M), dan CTA-Mont3 (CTAmontmorilonit dengan konsentrasi CTAB 0,072 M). Berdasarkan tabel 2, sampel CTA-Mont1 mengalami peningkatan basal spacing menjadi 2,35 nm. Peningkatan ini memberikan bukti bahwa telah terjadi pertukaran ion $\mathrm{Na}^{+}$dengan $\mathrm{CTA}^{+}$.

Sampel CTA-Mont2 dan CTA-Mont3 mengalami kenaikan basal spacing masing-masing menjadi 2,16 nm dan 1,96 nm. Hasil tersebut menunjukkan bahwa besarnya konsentrasi surfaktan CTAB yang digunakan dalam interkalasi antarlapis montmorilonit tidak sebanding dengan peningkatan basal spacing dan jarak antarlapis montmorilonit. Hal ini dimungkinkan karena interaksi sesama surfaktan kationik dalam jumlah yang besar mempengaruhi interaksi antara surfaktan kationik tersebut dengan muatan negatif pada montmorilonit.

Tabel 2: Perbandingan hasil analisis XRD Ca-Mont dan CTA-Mont

\begin{tabular}{ccc}
\hline Sampel & $2 \theta\left(^{\circ}\right)$ & Basal spacing $\left(\mathrm{d}_{\text {oo1 }}\right)(\mathrm{nm})$ \\
\hline Ca-Mont & 5,55 & 1,59 \\
CTA-Mont1 & 3,75 & 2,35 \\
CTA-Mont2 & 4,09 & 2,16 \\
CTA-Mont3 & 4,5 & 1,96 \\
\hline
\end{tabular}

Setiap surfaktan memiliki konsentrasi minimum untuk membentuk misel (koloid asosiasi) yang dinamakan konsentrasi kritik misel (critical miselle concentration/cmc). Jika surfaktan memiliki konsentrasi lebih kecil dari $\mathrm{cmc}$-nya maka tidak terbentuk misel. Jika surfaktan memiliki konsentrasi cmc-nya atau lebih besar dari $\mathrm{cmc}$-nya maka akan terbentuk misel. Variasi konsentrasi surfaktan di atas $\mathrm{cmc}$-nya akan membentuk struktur berbeda-beda. Jumlah surfaktan yang terlalu sedikit tidak akan mampu membuka antarlapis montmorilonit menjadi lebih besar. Akan tetapi jika surfaktan diberikan dalam keadaan berlebih maka interaksi antar surfaktan kationik di luar antarlapis montmorilonit lebih dominan dan akan berkumpul membentuk koloid asosiasi sehingga lebih sulit untuk berinteraksi dengan muatan negatif pada antarlapis montmorilonit. Akibatnya, jumlah surfaktan yang dapat terinterkalasi dalam antarlapis montmorilonit menjadi lebih sedikit dan tidak mampu memperlebar jarak antarlapis montmorilonit secara optimal.

\section{Karakterisasi BET Lempung Terpilar Oksida Besi}

Perbandingan hasil analisis BET Ca-montmorilonit (Ca-Mont) dan hasil pilarisasi sampel CTA-Mont1 (disebut Oksida Besi-Mont1) dapat dilihat pada tabel 3. Tabel 3 memperlihatkan peningkatan jari-jari pori ratarata sampel awal Ca-Mont 5,76 nm menjadi 8,14 nm pada Oksida Besi-Mont1. Peningkatan ini disebabkan meningkatnya basal spacing montmorilonit setelah pilarisasi. Pilarisasi menyebabkan pori-pori montmorilonit tetap terbuka lebar dan terbentuk poripori baru yang ukurannya lebih kecil. Kedua hal tersebut dapat mengakibatkan luas permukaan meningkat menjadi $80,73 \mathrm{~m}^{2} / \mathrm{g}$ serta volume pori total meningkat menjadi $0,33 \mathrm{~cm}^{3} / \mathrm{g}$. Selain beberapa parameter tersebut, hasil analisis BET juga memberikan data mengenai perbandingan distribusi pori antara Ca-Mont dengan Oksida Besi-Mont1 yang diperlihatkan dalam gambar 6 .

Tabel 3: Hasil analisis BET Ca-Mont dan Oksida BesiMont1

\begin{tabular}{cccc}
\hline Sampel & $\begin{array}{c}\text { Jari-jari } \\
\text { pori rata- } \\
\text { rata }(\mathrm{nm})\end{array}$ & $\begin{array}{c}\text { Volume } \\
\text { pori total } \\
\left(\mathrm{cm}^{3} / \mathrm{g}\right)\end{array}$ & $\begin{array}{c}\text { Luas } \\
\text { permukaan } \\
\left(\mathrm{m}^{2} / \mathrm{g}\right)\end{array}$ \\
\hline $\begin{array}{c}\text { Ca-Mont } \\
\text { Oksida } \\
\text { Besi- } \\
\text { Mont1 }\end{array}$ & 5,76 & 0,15 & 52,83 \\
\hline
\end{tabular}

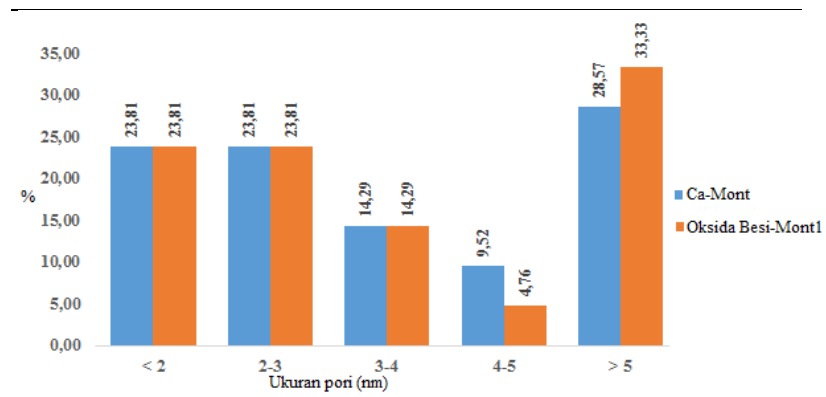

Gambar 6. Perbandingan distribusi pori Ca-Mont dengan Oksida Besi-Mont1

Gambar 6 menunjukkan bahwa terdapat perbedaan distribusi pori untuk pori ukuran 4-5 $\mathrm{nm}$ dengan pori ukuran > $5 \mathrm{~nm}$. Oksida Besi-Mont1 memiliki lebih banyak pori dengan ukuran $>5 \mathrm{~nm}$ daripada Ca-Mont. Perbedaan distribusi pori yang ditampilkan tidak begitu signifikan. Hal ini mengindikasikan bahwa pori baru yang terbentuk akibat pemilaran jumlahnya tidak cukup signifikan. Akan tetapi pelebaran pori-pori dalam montmorilonit akibat pilarisasi berkontribusi pada peningkatan volume pori dan luas permukaan Oksida Besi-Mont1. 


\section{Kesimpulan}

Surfaktan CTAB 0,024 M dapat meningkatkan basal spacing lempung paling tinggi sebesar 2,35 $\mathrm{nm}$ serta terjadi peningkatan jari-jari pori rata-rata, luas permukaan, serta volume total Oksida Besi-Mont1 secara berturut-turut menjadi $8,14 \mathrm{~nm}, 80,73 \mathrm{~m}^{2} / \mathrm{g}$, dan $0,33 \mathrm{~cm}^{3} / \mathrm{g}$.

\section{Daftar Pustaka}

[1] IP Okoye, C Obi, Synthesis and characterization of Al-pillared bentonite clay minerals, Research Journal of Applied Sciences, 6, 7, (2011) 447-450

[2] CB Molina, JA Casas, AH Pizarro, JJ Rodriguez, Pillared clays as green chemistry catalysts: application to wastewater treatment, Clay: Types, Properties and Uses, (2011) 435-474

[3] E. Dvininov, E. Popovici, R. Pode, L. Cocheci, P. Barvinschi, V. Nica, Synthesis and characterization of TiO2-pillared Romanian clay and their application for azoic dyes photodegradation, Journal of Hazardous Materials, 167, 1, (2009) 1050-1056 http://dx.doi.org/10.1016/j.jhazmat.2009.01.105

[4] Fatma Tomul, Adsorption and catalytic properties of Fe/Cr-pillared bentonites, Chemical Engineering Journal, 185-186, (2012) 380-390 http://dx.doi.org/10.1016/j.cej.2012.01.094

[5] Qi-ying Wang, Zi-li Liu, Han-bo Zou, Zhao-hui Zhao, Xing-chuan Wei, Effect of surfactant modification on the desulfurization performance of Zn/Ti-PILCs adsorbent, Journal of Fuel Chemistry and Technology, 39, 3, (2011) 203-206 http://dx.doi.org/10.1016/S1872-5813(11)60018-2

[6] Lei Wang, Weiya Yang, Chunling Xin, Fengxiang Ling, Wanfu Sun, Xiangchen Fang, Ruochen Yang, Synthesis of nano-zeolite IM- 5 by hydrothermal method with the aid of PEG and CTAB, Materials Letters, 69, (2012) 16-19 http://dx.doi.org/10.1016/j.matlet.2011.11.073

[7] Peng Yuan, Faïza Annabi-Bergaya, Qi Tao, Mingde Fan, Zongwen Liu, Jianxi Zhu, Hongping He, Tianhu Chen, A combined study by XRD, FTIR, TG and HRTEM on the structure of delaminated $\mathrm{Fe}$ intercalated/pillared clay, Journal of Colloid and Interface Science, 324, 1, (2008) 142-149 http://dx.doi.org/10.1016/j.jcis.2008.04.076

[8] Weihong Xue, Hongping He, Jianxi Zhu, Peng Yuan, FTIR investigation of $\mathrm{CTAB}-\mathrm{Al}-$ montmorillonite complexes, Spectrochimica Acta Part A: Molecular and Biomolecular Spectroscopy, 67, 3, (2007) 1030-1036 http://dx.doi.org/10.1016/j.saa.2006.09.024

[9] Preeti Sagar Nayak, B. K. Singh, Instrumental characterization of clay by XRF, XRD and FTIR, Bulletin of Materials Science, 30, 3, (2007) 235-238 http://dx.doi.org/10.1007/s12034-007-0042-5

[10] Daimei Chen, Jian Chen, Xinlong Luan, Haipeng Ji, Zhiguo Xia, Characterization of anion-cationic surfactants modified montmorillonite and its application for the removal of methyl orange, Chemical Engineering Journal, 171, 3, (2011) 1150-1158 http://dx.doi.org/10.1016/j.cej.2011.05.013

[11] Mashael Alshabanat, Amal Al-Arrash, Waffa Mekhamer, Polystyrene/montmorillonite nanocomposites: study of the morphology and effects of sonication time on thermal stability, Journal of Nanomaterials, 2013, (2013) 9 http://dx.doi.org/10.1155/2013/650725 